\title{
Evaluating the psychosocial and mental health consequences of abuse among Jordanian women
}

\author{
A.M. Hamdan-Mansour, ${ }^{1}$ R.E. Constantino, ${ }^{2}$ K.R. Shishani, ${ }^{3}$ R. Safadi ${ }^{4}$ and R. Banimustafa ${ }^{5}$
}

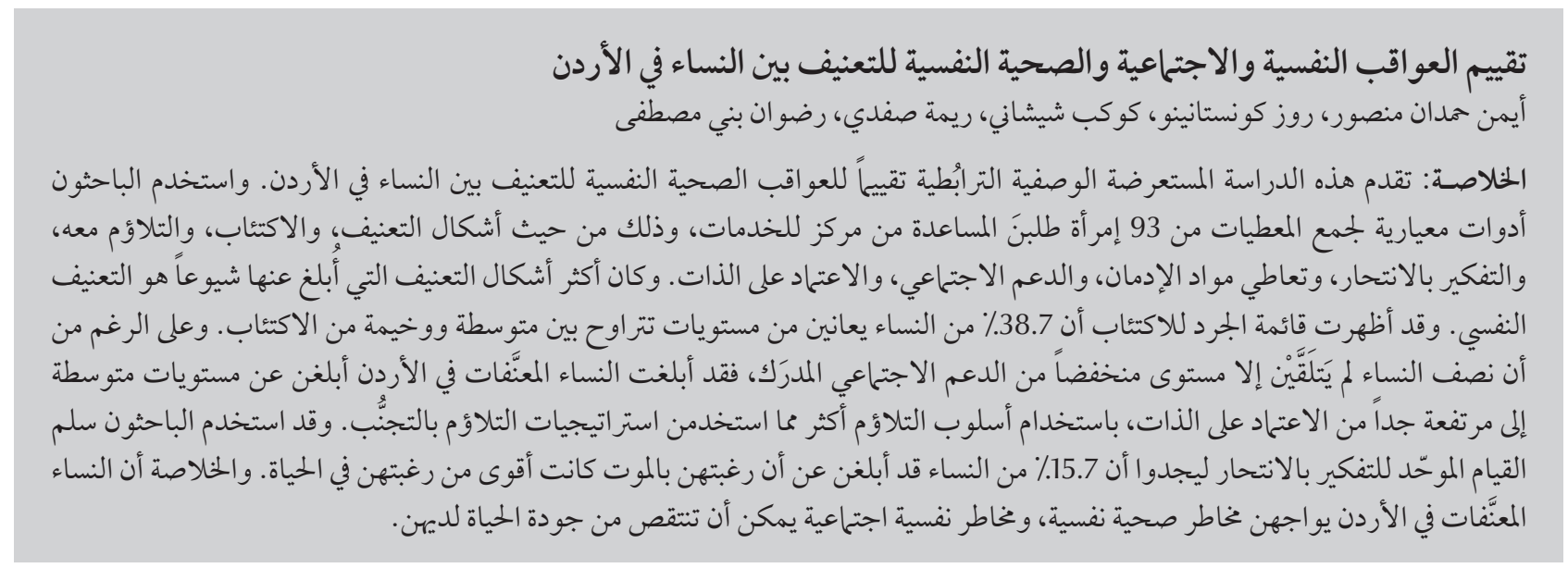

ABSTRACT This cross-sectional, descriptive, correlational study evaluated the mental health consequences of abuse among Jordanian women. Standard tools were used to collect data from 93 abused women seeking help at a welfare centre in relation to forms of abuse, depression, coping, suicidal ideation, substance use, social support and self-efficacy. The most commonly reported form of abuse was psychological abuse. Applying the Beck Depression Inventory showed that $38.7 \%$ of the abused women had moderate to severe levels of depression. Although half the women had a low level of perceived social support, abused Jordanian women reported moderate to very high levels of self-efficacy and used approach coping more frequently than avoidance coping strategies. Using the Modified Scale for Suicide Ideation, $15.7 \%$ of the women reported that the desire for death was stronger than the desire for life. Abused women in Jordan face mental health and psychosocial risks that could compromise their quality of life.

\section{Évaluation des conséquences psychosociales et mentales de la violence chez des femmes jordaniennes}

RÉSUMÉ La présente étude transversale, descriptive et corrélationnelle a évalué les conséquences de la violence sur la santé mentale de femmes jordaniennes. Des outils standards ont été utilisés pour recueillir des données auprès de 93 femmes ayant subi des violences et demandant de l'aide dans un centre de protection familiale. Ces données concernaient les types de violence, la dépression, les difficultés d'adaptation, les pensées suicidaires, la consommation de substances psychoactives, la recherche d'un appui social et le sentiment d'efficacité personnelle. Les violences les plus fréquemment rapportées étaient d'ordre psychologique. L'inventaire de la dépression de Beck a permis de révéler que 38,7 \% des femmes victimes de violences souffraient de dépression d'une intensité modérée à sévère. Même si la moitié des femmes avait le sentiment de recevoir un soutien social faible, les femmes jordaniennes avaient des niveaux modérés à très élevés d'efficacité personnelle et avaient plus souvent recours à des stratégies de confrontation que d'évitement. Selon les résultats sur l'échelle MSSI Modified Scale for Suicide Ideation, le désir de mourir était plus fort que le désir de vivre chez 15,7 \% des répondantes. Les femmes ayant subi des violences en Jordanie encourent des risques psychosociaux et de dégradation de leur santé mentale et ces risques pourraient altérer leur qualité de vie.

'Department of Community Health Nursing; ${ }^{4}$ Department of Maternal and Child Health Nursing, Faculty of Nursing, University of Jordan, Amman, Jordan.

${ }^{2}$ Department of Community and Health Systems, University of Pittsburgh School of Nursing, Pittsburgh, Pennsylvania, United States of America (Correspondence to H.M. Hamdan-Mansour: a.mansour@ju.edu.jo).

${ }^{3}$ Department of Community and Mental Health, Faculty of Nursing, Hashemite University, Zarqa, Jordan.

${ }^{5}$ Department of Psychiatry, Jordan University Hospital and Medical School, University of Jordan, Amman, Jordan.

Received: 02/05/10; accepted: 23/08/10 


\section{Introduction}

Intimate partner abuse is a major contributor to illness in women worldwide. No culture is immune from it. Globally, between $10 \%$ and $60 \%$ of women have at some time suffered abuse in their relationship, and about 5\% have experienced or are experiencing some form of abuse [1]. In Arab countries, 1 in 3 women is subjected to abuse [2]. Abused women suffer anxiety, depression, loss of perceived availability of social support and decreased ability to function as active members of society [3]. Cross-sectional and longitudinal studies showed that abuse places women at risk for emotional, cognitive and behavioural health problems [4].

Intimate partner abuse is a highly sensitive issue in Arab countries because of the structure of the society [5]. Previous studies [6,7] showed that between $30 \%$ and $45 \%$ of Jordanian women experienced at least one type of abuse, and physical abuse was the most commonly reported type. In another study, the highest rate of abuse against women was reported in women between 20 and 29 years of age, and batterers were mostly men between 30 and 39 years of age [8]. Intimate partner abuse has been reported at a higher rate in employed than in unemployed Jordanian women [8]. Some Jordanian women may lack the appropriate social support and management strategies to deal with abuse. It has been reported that $35 \%$ of Jordanian women experiencing intimate partner abuse do not resist their abuser, 24\% cried, $14 \%$ screamed, $12 \%$ returned to relatives, $8 \%$ defended themselves physically and only $0.06 \%$ reported to the police [9]. In Jordan, like many other Arab countries, there is a strong need to protect family reputation and honour. Women who disclose intimate partner abuse to formal agencies or the authorities are regarded as disloyal to the family [10]. Abused women in Jordan may suffer from serious injuries yet remain in the abusive relationship [6] because they feel they are not believed or do not receive adequate support for the disclosure of abuse [10].

Despite the literature on abuse, we still lack a clear understanding of the psychosocial and mental health consequences of abuse among help-seeking Jordanian women. The aim of this study therefore was to evaluate the mental health status of abused Jordanian women seeking help from a welfare centre. We applied standard tools to address the concepts of depression, suicide ideation, substance use and psychosocial concepts of self-efficacy, coping, stress and social support.

\section{Methods}

\section{Study design}

This was a cross-sectional, descriptive, correlational study conducted in Amman, Jordan. Data were collected using structured interviews from participants who had been referred to a welfare centre for professional and legal help.

\section{Participants}

A convenience sample of 95 women who had a history of intimate partner abuse and sought professional and legal help from the Jordanian Women's Union (JWU) were recruited. JWU was selected because it is the national and legal welfare centre providing longterm professional psychosocial and legal services for all women in Jordan, particularly abused ones. The study was conducted between 1 November 2008 and 28 February 2009. During that period, 150 women who were referred to the JWU to receive legal and professional counselling were asked to participate in the study; 95 women accepted and others refused for a range of reasons. The demographic characteristics of these women were no different from those who accepted. The inclusion criteria were age 18 years or older and reporting abuse during the last 12 months. Women diagnosed with any mental disorder were also excluded, as this study focused on examining deterioration in mental health status rather than assessing mental disorders as some of these deteriorations do not meet the formal criteria of the Diagnostic and Statistical Manual of Mental Disorders (4th edition) (DSM-IV). A total of 93 women completed the structured interview.

\section{Data collection}

\section{Ethical considerations}

Approval from the academic research committee of the Faculty of Nursing of the University of Jordan was obtained prior to data collection. Mental health professionals at the JWU served as liaisons and advocated to facilitate data collection. First, the liaison person from the JWU who provides counselling for the abused women invited women to participate in the study. Those who agree were seen by the researcher or one of the research team who explained the study to them. Trained research assistants in addition to the researchers were responsible for collecting data from the women. The researchers explained the purpose of the study, answered participants' questions and assured them about the confidentiality of the data collected. Women were informed that they would be asked questions related to their experience of abuse and their psychological and mental status. Then the research team screened all women who agree to participate to determine their eligibility. Those who met the inclusion criteria were asked to sign a consent letter. Participants were informed that they had the right to withdraw from the study at any time. The interviews were conducted in a private room provided by the JWU.

\section{Measurements}

All of the instruments were translated into Arabic language except for the Beck Depression Inventory (BDI) which was already available in Arabic. The translation and back translation protocol was carried out by experts in the language 
and the subject matter. Pilot testing of the translated instruments was carried out to assess participants' understanding, the clarity of words used and the time required for completing the questionnaires.

- Intimate partner abuse was measured using the Arabic version of the Abuse Scale developed by HaiYahia [5]. The scale consists of 4 parts corresponding to different forms of abuse: psychological abuse (16 acts); physical abuse (11 acts); sexual abuse (3 acts); and economic abuse (2 acts). All items ask the participants to identify the number of times they have been exposed to any form of abuse during the past 12 months. Responses range from never (0) to more than once (2). The scale has good reliability; Cronbach alpha ranges from 0.71 (economic abuse) to 0.92 (psychological abuse) and for the total scale it is 0.86 [5]. In our study Cronbach alpha ranged from 0.80 (sexual abuse) to 0.95 (psychological abuse) and was 0.94 for the total scale.

- Depression was measured using the Arabic version of the BDI [11]. The Arabic BDI consists of 21 items. Item responses range from 0 (absence of symptoms) to 3 (severe symptoms). The total scale ranges from 0 to 63 and is interpreted as follows: 0-9 (not depressed), 10-15 (mild depression), 16-23 (moderate depression), 24+ (severe depression). The score of 10 is the cut-off point between being depressed and not depressed. The test-retest $r$ was 0.88 and Cronbach alpha was 0.87 [11].

- Suicidal ideation was measured using the Modified Scale for Suicide Ideation (MSSI) [12]. MSSI is a revised version of the Scale for Suicide Ideation. The MSSI is an 18-item scale that contains 13 items from the SSI and 5 additional items. These new items are related to intensity of ideation, courage and competence to attempt and talking and writing about death. The MSSI was designed to be a semi-structured interview that could be administered by both professionals and paraprofessionals. The MSSI assesses suicide symptoms over the past year. Each item is rated on a 3-point scale and the ratings are summed to yield a total score ranging from 0 to 54 . In this study Cronbach alpha for this scale was 0.94 .

- Substance use was measured using domain I of the Drug Use Screening Inventory (DUSI-R) [13]. DUSI-R is a self-report scale that asks questions related to use of substances. Substance use is an interval scaled variable where the individual identifies the number of times he/she used the substance. Responses ranged from 0 (none) to 5 (more than 20 times). The scale has good reliability with Cronbach alpha of 0.72 [13]. In this study, Cronbach alpha for this scale was 0.77 .

- Coping skills were measured using the Ways of Coping Scale (WOC) [14]. WOC is a self-report instrument that measures coping strategies. It asks participants to recall a recent stressor and then rate how often they have used a specific behaviour (66 behaviours) to cope with that particular stressor. Scale scores are additively derived from individual items and divided by a total score to provide relative scores for 8 scales: confrontive coping, accepting responsibility, distancing, escape avoidance, planful problem-solving, positive reappraisal, self-controlling and seeking social support. In a factor analytic study [14], the internal consistency ranged from 0.66 to 0.79 for the 8 factors. Evidence for good criterion and construct validity of the scale was reported with a community sample. In this study Cronbach alpha for this scale ranged form 0.78 (confrontive coping) to 0.89 (escape avoidance) and for the total scale was 0.88 .
- Self-efficacy was measured using the Self Efficacy Scale for Battered Women (SESFBW) [15]. This instrument is specific to crisis events and has demonstrated acceptable psychometric properties. The SESFBW is a 12 -item $100 \mathrm{~mm}$ visual analogue scale in which 0 indicates very low self-efficacy, 50 indicates moderate self-efficacy and 100 indicates very high self-efficacy. The scale measures a battered woman's perception about her capability of performing a behaviour or a set of behaviours in a specific crisis situation related to abuse. Cronbach alpha was 0.88. Construct validity was shown by support of predictions using a theory testing approach [15]. In this study Cronbach alpha for this scale was 0.86 .

- Perceived social support was measured using the Perceived Social Support Scale (PSS) [16]. The PSS is a 40-item scale that measures the nature of the perceived social support from family and friends. The PSS consists of 2 subscales: perceived social support from family and perceived social support from friends. Each of the subscale scores ranges from 0 to 20. Lower scores indicate lower perception of perceived social support. The scale demonstrated good internal consistency ranging from 0.88 to 0.91 for the family subscale and from 0.84 to 0.90 for the friends subscale [16]. In this study Cronbach alpha for the friends subscale was 0.76 and for the family subscale was 0.83 .

\section{Statistical analysis}

SPSS, version 15 was used to analyse the data. Variables were described using the central tendency measures (mean and median) and the dispersion measures [standard deviation (SD) and range]. Pearson correlation coefficient $(r)$ was used to examine the relationship between the variables. Mann-Whitney U test was used to examine for differences and Kendall tau- $b$ was used to examine correlations between ordinal variables. 


\section{Results}

\section{Demographic characteristics}

Participants' ages ranged from 15 to 54 years, with a mean age of 32.4 (SD 8.3 ) years. Marital status was $38.7 \%$ married, $41.9 \%$ divorced, $11.8 \%$ separated (still married but living in their parents' house) and $7.5 \%$ single. Of the total sample, only 29.0 had a bachelor or masters degree, while $32.3 \%$ had completed secondary education. In addition, $64.4 \%$ of the women reported not working and $35.4 \%$ were currently working.

\section{Prevalence and type/form of intimate partner abuse}

As shown in Table 1, psychological abuse was the most reported form of abuse. Items describing the abuser yelling at the woman or ending a discussion abruptly and making the decision he wants were experienced more than once by $78.4 \%$ and $72.2 \%$ of women respectively. Other descriptions of psychological abuse included belittling the way the woman dressed and her appearance (34.1\%).

Physical abuse was described as the woman being pushed, kicked, knocked down or pulled hard more than once during the past 12 months ( $55.7 \%$ and $50.0 \%$ respectively). Other descriptions of physical abuse occurring more than once during the past 12 months included being slapped (42.5\%) and being threatened with a knife (19.5\%).

Sexual abuse was described as the abuser trying to have sex with them without their consent (25.9\%), using crude and belittling language, expressing dissatisfaction with their sexual relationship in an insulting and degrading way (26.7\%) and having sex with them using physical force (24.7\%). In addition, nearly half of the women reported that their abuser withheld money (48.8\%) or took money from them $(45.1 \%)$.

\section{Psychosocial and mental health consequences}

\section{Depression}

The BDI scores showed that the abused women suffered from severe depressive symptoms, with a mean score of 20.1 (SD 13.1) (Table 2). Among these women, $38.7 \%$ had a score of $\geq 24$ indicating severe depression, $47.3 \%$ had a score of 16-24 indicating moderate to severe level of depression, while only $14.0 \%$ scored $\leq 9$ or less indicating mild depressive symptoms.

\section{Social support}

Abused women had a low level of social support, as reflected in mean scores of 32.1 (SD 7.9) and 30.8 (SD 8.3) on perceived social support from friends and family respectively. Only $24.7 \%$ $(n=23)$ of the women had a score of 36-37 on the perceived social support from friends and family respectively and $45.2 \%(n=42)$ of the women reported a score of $\geq 31$ on both scales.

\section{Self-efficacy}

The results indicated that women had moderate to very high level of self-efficacy. More than half of the women scored $\geq 70$ on all items of the self-efficacy scale, except for item 5 (find people to be with when you feel isolated), for which $50 \%$ of the women had a score of $\geq 60$. The mean scores for all items of self-efficacy were $\geq 60$ [25th percentile (P25) was 100 for all items except item 5].

\section{Coping skills}

In general, the results showed that women used approach coping strategies (positive reappraisal, confrontive coping, planful problem-solving and seeking social support) [mean score 69.4 (SD 15.1)] more than avoidance coping (distancing coping, self-controlling, accepting responsibility and escape avoidance [mean score 59.5 (SD 12.6)].

Regarding approach coping, women reported using positive reappraisal coping (P25 225) more than any form of coping strategies. Other forms of approach coping had moderate scores with means ranging from 15-16 (P25 was $\geq 19$ ). Other results on approach coping showed that women used positive reappraisal coping strategies more frequently than the other forms of approach coping.

The highest reported form of avoidance coping strategy was escape avoidance coping [mean score 18.6 (SD 5.0)]. The lowest form of avoidance coping strategy used was accepting responsibility [mean score 9.9 (SD 3.2)].

Distancing and self-controlling coping strategies were equally used by women [mean score 15]. P25 was $\geq 25$ on the escape avoidance coping strategies and P25 was 19 in distancing coping strategies and 18 in self-controlling coping strategies.

Women showed less use of accepting responsibility as their preferred coping strategy ( $\mathrm{P} 75$ was $\leq 12$ ).

\section{Suicide ideation}

Assessment of suicidal ideation showed that $62.5 \%(n=58)$ of the women reported never wishing death and $77.4 \%$ $(n=72)$ had never thought seriously of attempting suicide. On the other hand, $35.5 \%$ of abused women had weak to strong wish for death compared to $82.8 \%(n=77)$ of them who had a weak to strong wish for life.

The MSSI showed those with no serious attempt to suicide $(n=89), 65.2 \%$ $(n=58)$ had a desire for life stronger than death, $82.0 \%(n=73)$ took precautions to save their lives and $88.8 \%$ ( $n$ $=79$ ) had weak intention to end their lives. However, 17 (19.1\%) of these women reported an equal desire for life and death and $14(15.7 \%)$ reported that the desire for death was stronger than the desire for life.

\section{Substance use}

Data on substance use showed that none of the abused women had used cocaine, marijuana or hallucinogens in the past 12 months. One woman reported using heroine and volatile inhalants. The 


\begin{tabular}{|c|c|c|c|}
\hline \multirow[t]{2}{*}{ Item } & Never & Once & More than once \\
\hline & $\%$ & $\%$ & $\%$ \\
\hline \multicolumn{4}{|l|}{ Psychological abuse } \\
\hline Yelled at you & 14.8 & 6.8 & 78.4 \\
\hline Ended a discussion and made the decision that he wants & 18.9 & 8.9 & 72.2 \\
\hline Insulted and damned you or called you bad names & 23.9 & 9.1 & 67.0 \\
\hline Prevented you from doing something you wanted & 23.9 & 11.4 & 64.8 \\
\hline Stormed out of the house after an argument, cursing and yelling at you & 20.9 & 15.1 & 64.0 \\
\hline $\begin{array}{l}\text { Degraded and insulted you or your acquaintances in an attempt to } \\
\text { intimidate you }\end{array}$ & 30.6 & 9.4 & 60.0 \\
\hline Threatened to throw something at you and said things to intimidate you & 31.0 & 9.2 & 59.8 \\
\hline Degraded your family, relatives or friends by humiliating or cursing them & 28.4 & 12.5 & 59.1 \\
\hline Gave you dirty looks in an attempt to intimidate you & 31.4 & 10.4 & 58.1 \\
\hline Threatened you with divorce or separation & 38.6 & 10.2 & 50.0 \\
\hline Showed little attention during your pregnancy and sickness & 37.9 & 12.6 & 48.3 \\
\hline $\begin{array}{l}\text { Requested or forced you to do something with the intention of insulting or } \\
\text { humiliating you }\end{array}$ & 48.3 & 3.5 & 48.2 \\
\hline $\begin{array}{l}\text { Reprimanded or scolded you while belittling your thoughts, beliefs, and } \\
\text { attitudes }\end{array}$ & 41.9 & 14.0 & 44.0 \\
\hline $\begin{array}{l}\text { Accused you of being lazy, indifferent, and failing to fulfil your obligations } \\
\text { toward him and the household }\end{array}$ & 48.3 & 10.3 & 41.4 \\
\hline $\begin{array}{l}\text { Belittled the way you dress, your body, and the way you keep up your } \\
\text { appearance }\end{array}$ & 56.8 & 9.1 & 34.1 \\
\hline $\begin{array}{l}\text { Tried to control your behaviour by investigating, interrogating, and } \\
\text { following you }\end{array}$ & 50.6 & 16.5 & 32.9 \\
\hline \multicolumn{4}{|l|}{ Physical abuse } \\
\hline Pushed you, kicked you, or tried to knock you over & 33.0 & 11.4 & 55.7 \\
\hline Pushed or pulled you hard & 39.8 & 10.2 & 50.0 \\
\hline Slapped you & 42.5 & 14.9 & 42.5 \\
\hline Threw, kicked or broken something while arguing with you & 46.5 & 14.0 & 39.0 \\
\hline Attacked you with his hands on different parts of your body & 45.5 & 17.0 & 37.5 \\
\hline Pulled your hair or yanked your clothes & 52.3 & 17.0 & 30.7 \\
\hline $\begin{array}{l}\text { Tried to choke you or placed his arms around your neck in an attempt to } \\
\text { harm you }\end{array}$ & 65.9 & 8.0 & 26.1 \\
\hline Attacked you with a stick, a belt or other object of that kind & 62.1 & 12.6 & 25.3 \\
\hline Threatened you with a knife or another sharp implement & 69.0 & 11.5 & 19.5 \\
\hline Attacked you with a dangerous implement such as a knife or metal rod & 76.7 & 5.8 & 17.4 \\
\hline Attacked you with household equipment (e.g., a chair) & 75.9 & 9.2 & 14.9 \\
\hline \multicolumn{4}{|l|}{ Sexual abuse } \\
\hline $\begin{array}{l}\text { Expressed dissatisfaction with your sexual relationship in an insulting and } \\
\text { degrading way }\end{array}$ & 65.8 & 7.6 & 26.7 \\
\hline Tried to have sex with you without your consent using language & 64.2 & 9.9 & 25.9 \\
\hline Had sex with you using physical power & 69.1 & 6.2 & 24.7 \\
\hline \multicolumn{4}{|l|}{ Behavioural and economical abuse } \\
\hline Withheld money from you & 44.0 & 7.1 & 48.8 \\
\hline Took money from you & 42.7 & 12.2 & 45.1 \\
\hline
\end{tabular}


substances most commonly used were caffeine (82.8\%), painkillers (61.3\%) and nicotine $(26.9 \%)$. Three women (3.3\%) reported using alcohol, 5 (5.5\%) took stimulants and 10 (11.8\%) took tranquillizers.

\section{Correlations between psychosocial indicators}

Pearson correlation coefficients showed that depression had a significant and negative correlation with self-efficacy $(r$ $=-0.47, P>0.001)$ and perceived social support from the family $(r=-0.27, P$ $>0.05$ ) (Table 3). Self-efficacy had a significant and positive correlation with approach coping strategies $(r=0.26$, $P>0.05)$. Moreover, perceived social support from friends had a significant and negative correlation with avoidance coping $(r=-0.25, P>0.05)$.

Items 2 (wish to die) and 4 (serious desire to attempt suicide) on the MSSI was recoded into "yes" or "no" to explore whether there was a difference in suicidal ideation in relation to depression, social support, self-efficacy and coping. The Mann-Whitney test showed that those who wished to die had significantly lower depressive scores $(U=545, P=0.002)$ and lower approach coping strategies $(U=663$, $P=0.04)$. Furthermore, there was a significant difference between women who had a serious desire to attempt suicide and those who did not in relation to the presence of depressive symptoms $(U=217, P=002)$ and self-efficacy scores $(U=217, P=0.003)$.

\section{Differences related to demographic and personal characteristics}

In relation to demographic characteristics, the analysis showed that there was a significant and negative correlation between husband-wife age difference and distancing coping strategies $(r=-0.21, P>0.05)$ and positive reappraisal coping strategies $(r=-0.36, P$ $>0.001)$. Regarding the length of marriage, the analysis showed that length

\begin{tabular}{|c|c|c|c|}
\hline \multirow[t]{2}{*}{ Variable } & \multicolumn{3}{|c|}{ BDI scores } \\
\hline & Mean (SD) & Min. & Max. \\
\hline Depression & $20.1(13.1)$ & 0 & 49 \\
\hline Perceived social support-friends & $32.1(7.9)$ & 1 & 60 \\
\hline Perceived social support-family & $30.8(8.3)$ & 3 & 65 \\
\hline Ways of coping scale & $128.6(25.3)$ & 14 & 184 \\
\hline Approach coping & $69.4(15.1)$ & 8 & 96 \\
\hline Positive reappraisal & $21.8(4.6)$ & 5 & 24 \\
\hline Confrontive coping & $15.2(4.3)$ & 3 & 24 \\
\hline Planful problem-solving & $16.4(4.3)$ & 3 & 24 \\
\hline Seeking social support & $16.2(4.8)$ & 1 & 24 \\
\hline Avoidance coping & $59.3(12.6)$ & 6 & 88 \\
\hline Distancing coping & $15.3(4.4)$ & 1 & 24 \\
\hline Self-controlling & $15.7(3.6)$ & 4 & 24 \\
\hline Accepting responsibility & $9.9(3.2)$ & 4 & 16 \\
\hline Escape avoidance & $18.6(5.0)$ & 5 & 24 \\
\hline
\end{tabular}

$S D=$ standard deviation.

of marriage had a significant negative correlation with confrontive coping $(r=$ $-0.30, P>0.001)$, distancing coping $(r=$ $-0.30, P>0.001)$, seeking social support $(r=-0.23, P>0.05)$, planful problem solving $(r=-0.30, P>0.001)$ and positive reappraisal $(r=-0.27, P>0.05)$.

To examine the difference in psychosocial variables among women in relation to employment status (employed versus not employed), type of marriage (traditional versus non-traditional), and type of relationship with the abuser (family member versus non-family member), Kendall tau-b showed that the only significant relationship was between depression and type of relationship ( $\kappa=-0.20, P=0.16)$. Regarding suicidal ideation, the Mann-Whitney test showed a significant difference in age between those who had a serious desire for suicide and those who did not $(U=272, P=0.017)$.

\section{Discussion}

This study focused on examining the experience of abuse and its mental health consequences among Jordanian women, rather than on formally defined mental disorders. This issue has never been addressed among Arab women and particularly Jordanian ones.

The study found that the most frequently self-reported forms of abuse were physical and psychological. Physical abuse included threatening with a knife or other household equipment, slapping, beating, knocking down, pushing, pulling and kicking. Psychological abuse included criticizing the woman's appearance and accusing her of being a failure. These findings are consistent with previous studies in Jordan, which identified the most prevalent forms of abuse against women as physical abuse, forceful marriage, lack of access to education and right to inheritance, sexual harassment and unfair laws [6,7]. Abuse, regardless of its form, endangers the quality of life and health and reduces the productivity of women by suppressing their ability to express and participate as effective members of society [17]. The psychological and social consequences of abuse are multifaceted. The results of this study correspond in general with previous national and international studies showing that abused women 


\begin{tabular}{|c|c|c|c|c|c|}
\hline \multirow[t]{2}{*}{ Variable } & \multicolumn{5}{|c|}{ Pearson correlation coefficients } \\
\hline & Self-efficacy & $\begin{array}{l}\text { Ways of } \\
\text { coping }\end{array}$ & $\begin{array}{l}\text { Perceived social } \\
\text { support from } \\
\text { family }\end{array}$ & $\begin{array}{l}\text { Perceived social } \\
\text { support from } \\
\text { friends }\end{array}$ & Depression \\
\hline Self-efficacy & - & $0.23^{*}$ & -0.10 & -0.14 & $-0.47^{* *}$ \\
\hline Ways of coping scale & & - & 0.14 & $0.21^{*}$ & 0.10 \\
\hline Perceived social support-family & - & - & - & $0.34^{* *}$ & $-0.27^{*}$ \\
\hline Perceived social support-friends & - & - & - & - & 0.17 \\
\hline Depression & - & - & - & - & - \\
\hline
\end{tabular}

${ }^{*} P<0.05$ (2-tailed); ${ }^{*} P<0.01$ (2-tailed).

suffer a number of mental health and psychosocial problems such as depression, anxiety and lack of social support $[3,18]$. In the present study more than half of the abused women reported a moderate to severe level of depression, and the majority of them reported having a low level of social support from their family.

The encouraging findings of this study was that the abused Jordanian women reported moderate to very high levels of self-efficacy, used approach coping more frequently than avoidance coping strategies and perceived high levels of social support from friends. The use of approach coping skills more frequently than avoidance coping is an extremely important finding. Women reporting having strong support from their friends may be better equipped to stand up for themselves and face their problems rather than trying to escape from them. The results can be interpreted from different perspectives. It could be that women may tend to overestimate or report the abuse acts or that they were receiving support from friends and others that gave them the power and motivation to cope with their unpleasant experiences.

We also found that women who reported low levels of depressive symptoms reported high self-efficacy. This may relate to the women's confidence in their ability to deal with the abusive events and, therefore, their ability to use approach coping more frequently than avoidance coping styles. According to Folkman and Lazarus [14], using approach coping strategies is conceptually associated with better emotional and cognitive outcomes. This implies that women, in this study may have used support from friends and other family members and used their high self-efficacy and self-motivation to manage and adapt to the unpleasant consequences of the abusive relationship. This may explain also the tendency of abused women in this study to use approach coping skills more than avoidance coping skills. For some women, the experience of abuse seems to have provoked them to make changes and increase their awareness about their right to be respected as a dignified human being. The results in this study are consistent with previous national and international studies which emphasize the impact of abuse on the life of women and the effects of abuse on their continued adaptation and contribution to society $[3,5,7]$.

A low rate of suicidal thoughts or suicidal attempts was reported by almost two-thirds of the women in this study. The high rate of depressive feelings with a very low report of suicidal thought or attempts raises a question about the connection between depression and suicide. However, religious beliefs in this community ( $94 \%$ of the study were Muslims) may provide an explanation. Inflicting harm on self or others is prohibited in Islamic law and this may serve as a protective factor against attempting to commit suicide, even if it did not prevent women from contemplating suicide.

Onelimitation of this study is that the sample size was not big enough to make the results generalizable. Another limitation is that women who participated in this study were those who were aware about the centre for abused women and some may have received some help sessions, while women who do not know about the centre were not included. The sample represented women who were victims of abuse and was not a sample of the general public.

\section{Conclusion}

The study suggests that abused women in Jordan face mental health and psychosocial risks that could compromise their quality of life. Mental health professionals should understand the significance of the mental health consequences of abuse. There is a need to initiate a national collaborative effort that aims to increasing the public awareness that women who are experiencing intimate partner abuse and are seeking help should be given social support and encouragement in their ability to face and approach the experience instead of being blamed and shamed for staying in the relationship. Such a national agenda would encourage capacity-building for health professionals to manage and improve the psychosocial and mental health care services in Jordan.

\section{Acknowledgement}

This study was funded by the World Health Organization Regional Office for the Eastern Mediterranean, grant no. TSA/08/00140. 


\section{References}

1. McFarlane J, Groff J. Prevalence of partner violence against 7443 African American, White, and Hispanic women receiving care at urban public primary care clinics. Public Health Nursing, 2005, 22:98-107.

2. Douki $\mathrm{S}$ et al. Violence against women in Arab and Islamic countries. Archives of Women's Mental Health, 2003, 6:165-171.

3. Constantino R, Crane P, Kim Y. Effects of a social support intervention on health outcomes in residents of a domestic violence shelter: A pilot study. Issues in Mental Health Nursing, 2005, 20:105.

4. Sutherland CA, Sullivan CM, Bybee DI. Effects of intimate partner violence versus poverty on women's health. Violence Against Women, 2001, 7:1122-1143.

5. Haj-Yahia MM. Wife abuse and battering in the socio-cultural context of Arab society. Family Process, 2000, 39:237-255.

6. Al-Hadidi M, Jahshan H. Family violence. In: Handbook of family violence. Amman, Family Guidance and Education, the National Council for Family Affairs, 2000:31-48.

7. Gharaibeh M, Al-Ma'aitah R. The cultural meaning of violence against women: Jordanian women's perspective. Guidance and Counseling, 2002, 18:2-9.

8. Prevalence offamily violence in Al-Zarqa city, Zarqa. Jordan. Amman, Family Guidance and Education Center, 2001.

9. Violence against women in Jordan, Amman. National Council of Family Affairs, 2005
10. Ratrout S, Attar H. Expected social consequences for Institutionalizing abused women from social workers perspective. Amman, Ministry of Social Development, 2002.

11. Hamdi N, Nizam AH, Sabir AT. Psychometric properties of the Arabic version of Beck Depression Inventory. Dirasat: Human and Social Sciences, 1988, 10:30-40.

12. Miller LW et al. The Modified Scale for Suicide Ideation: reliability and validity. Journal of Consulting and Clinical Psychology, 1986, 54:724-725.

13. Tarter RE, Hegedus AM. The drug use screening inventory: its application in the evaluation and treatment of alcohol and other drugs. Alcohol Health and Research World, 1991, 15:65-75.

14. Folkman S, Lazarus RS. Manual for the ways of coping questionnaire. Palo Alto, California, Consulting Psychologist Press, 1988.

15. Varvaro FF, Palmer M. Promotion of adaptation in battered women: a self- efficacy approach. Journal of the American Academy of Nurse Practitioners, 1993, 5:264-270.

16. Procidano M, Heller K. Perceived social support scale. American Journal of Community Psychology, 1983, 11:1-24.

17. Ahrens C. Being silenced: the impact of negative social reactions on the disclosure of rape. American Journal of Community Psychology, 2006, 38:263-274.

18. McFarlane $\mathrm{J}$ et al. An intervention to increase safety behaviors of abused women. Nursing Research, 2002, 51:347-354.

\section{Encouraging letters to the Editor}

EMHJ welcomes letters from readers with their comments and observations on papers published in the Journal in order to stimulate scientific discourse on and appraisal of the research published. Letters found appropriate are published in our Letters to the Editor section. Readers can submit their letters to the Editor-inChief at : emhj@emro.who.int. 